\title{
Archiving and curating activist design on Instagram: the 2018 Brazilian presidential election visual narratives
}

\author{
Didiana Prata \\ PhD. Candidate in Design at FAU-USP - University of São Paulo \\ R. Aliados, 793 05088-01 São Paulo Brazil \\ didianaprata@usp.br
}

\begin{abstract}
This paper addresses the new visual archives that emerged in the context of the dissident design created during the 2018 presidential election in Brazil. Considered the most fratricide dispute of our political history between two opposing candidates representing completely different points of view, these two groups fought a real battle on social networks. The material collected in this research focused on dissident visual narratives, on message-images (posters of the networks era) produced by ordinary citizens and by activist groups. Many collectives of artists, designers and independent groups have also organized their message-images using algorithm criteria, with \#s, on Instagram (\#designativista, \#desenhosopelademocracia, \#designdissidente, \#coleraalegria, \#elenao).

This curatorial work aims at discussing the new vocabulary of dissident design on Instagram.

These narratives represent the database aesthetics and offer a rich material to discuss the new status of the image in the mass communication of social networks. They have a potential to represent the digital graphic memory of Brazilian political, social and artistic history, and constitute a fundamental element in the archeology of aesthetics of dissident visual narratives. Through visual examples edited from the main \#s mentioned above, this paper intends to discuss how to classify and archive big amounts of data that are already being lost in the constant stream of social networks. The article also suggests new parameters for cataloging images by using Artificial Intelligence and supervised learning machines to develop image classifiers specially created for this research.
\end{abstract}

Activist design. Data base aesthetics. Social networks graphic language. Artificial intelligence. Archiving.Graphic memory

\section{INTRODUCTION}

This article presents a selection of activist narratives in Brazil and some criteria for cataloging these images posted on Instagram. Through data visualization and a communication design curatorship, we intend to discuss the aesthetic vocabulary of these collective manifestations as well as the relevance of archiving these images using new image classification methodologies. In order to illustrate this discussion, we will present images produced from facts related to political events and the presidential election in Brazil in 2018.

When we analyze the huge number of activist posts on Instagram, we realize that there is a unique poetics in the images produced. The rich variety of posts created and mediated in different languages such as handmade and vector illustration, documentary photographs of demonstrations and events, memes, collages, stencils, embroideries to name a few - flooded social networks like a waterfall that flows into a river, producing a stream of potent and continuous water consisting of monothematic fragments that had rarely been observed in Brazilian social media (Instagram and Facebook). The aesthetics of these posts (message-images) introduces a new digital language of its own, inherent to the medium in which the image was produced and conveyed. These artifacts constitute the contemporary Brazilian graphic memory.

Archiving and classifying the dissident production of over 800,000 images on Instagram during this time required the use of new strategies and the creation of parameters for cataloging and viewing activist images. We will begin this discussion with a qualitative analysis resulting from a cognitive 
process - the curator's eye and a careful selection of the different representations of graphic languages and the characteristics of the emerging aesthetics of online digital culture. The narrative samples presented here elucidate the relevance of these graphic pieces and raise questions regarding the archiving of this ephemeral production:

how to archive in order to classify and how to classify in order to archive?

We will also discuss the importance of quantitative analysis and the use of artificial intelligence in the project of image classifiers. The design of these labelers has based on some composition patterns previously established by the author. The use of deep learning brought new perspectives for this research and it is been developed by a interdisciplinaire group at CIAAM-USP (Center of Artificial Intelligence and Machine Learning at University of São Paulo Innovation Center).

As methodology for the data collection, precataloging and editing of this set of images, the following procedures were used:

(i) The "\#" algorithm preceded by a keyword for data visualization: the contemporary image caption.

(ii) The capturing of Instagram images via Stogram software in order to download all images posted on Instagram through the chosen \#.

(iii) The creation of aesthetic parameters and categories of image types to classify captured images.

(iv) The use of supervised machine learning to optimize and extend quantitative image classification using labels capable of recognizing thousands of images within the seven aesthetic classifications used by the author as features for supervised training. A partial result of this phase of the work, which constitutes a part of the author's ongoing doctoral research, will be presented.

Finally, in order to identify the aesthetic vocabulary of this online activist imagery, we will address the potential of such activist narratives - edited and categorized based on this classification criterion within the realm of communication design. We also intend to point out the reasons why we should archive this ephemeral mass production as Brazilian graphic memory.

\section{POLITICAL CONTEXT}

Firstly, a brief summary of the political context and the main events that caused the circulation of the imagery (set of images) in question is in order.

Considered the largest fratricidal dispute in our political history between two candidates representing completely antagonistic views, this turbulent historical period has generated an unprecedented mobilization of the population throughout the country.

The 2018 presidential election campaign followed the former president Dilma Rousseff's impeachment process in 2017. On one end of the dispute was Fernando Haddad, the former mayor of São Paulo, a university professor, representing the left-wing party, the Workers' Party (PT), namely the party of former president Rousseff and also of former president Luiz Inácio Lula da Silva, popularly known as Lula. Lula served two terms (with $87 \%$ of approval and popularity at the end of his second term, the highest approval rating of a president in Brazil). Candidate Haddad replaced Lula as an opponent after his arrest - which was apolitical maneuver engendered to accuse him of money laundering, ideological falsity and asset concealment and prevent him from running in the election. On the other end ran Jair Bolsonaro, a former army captain and a former congressman with 7 consecutive terms ( 27 years in office), with a dictatorial, homophobic, evangelical and far-right agenda.

Fourteen presidential candidates ran in the first round on October 7, 2018. Jair Bolsonaro and Fernando Haddad were the most voted candidates and faced a run-off on October 27. The weeks before the second round were the most intense weeks of the entire election campaign and, consequently, the most fertile period of activist production. The demonstrations were the largest multi-party protests against candidate Jair Bolsonaro. It was a stance against homophobic, racist and facist statements of the then candidate.

The various graphic language productions gathered here visually represent the point of view of centerleft protesters, motivated by the imminent run-off vote.

In order to make this selection, we also took into account the production of pro-Bolsonaro posts, which consisted mostly of images of the candidate in his everyday life, memes and fake news about his opponent, Haddad. Bolsonaro created an extremely strong political articulation by planting fake news in WhatsApp groups (encrypted and consequently more difficult to track). The 

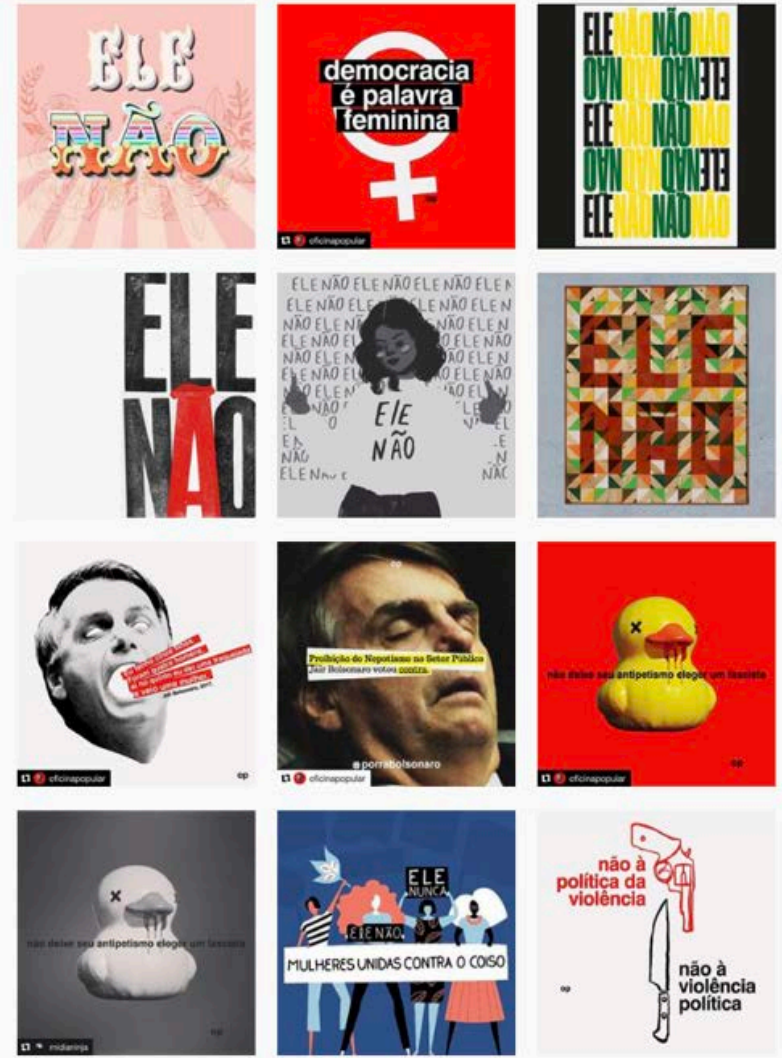

Figure 1: captured images from the \#elenão (not him) feed on Instagram.

candidate's own Twitter account was the second main channel used. Facebook and Instagram were used mostly as repost channels of the content that had been posted on private WhatsApp groups and Twitter accounts. The posts and imagery produced by his supporters would call for another paper, more focused on his intelligent strategy of network use, rather than the aesthetic quality of the imagery conveyed.

Jair Bolsonaro won the election with $55.13 \%$ of the popular vote while Fernando Haddad took only $44.87 \%$ of votes. Bolsonaro aligns with Trump's conservative and nationalist politics, has become known in the international media as the "Brazilian Trump", and has announced measures such as the allowance of gun possession for civilians (2019) and decisions that move Brazil away from the international environmental agenda from the UN, among other very controversial ideological measures.
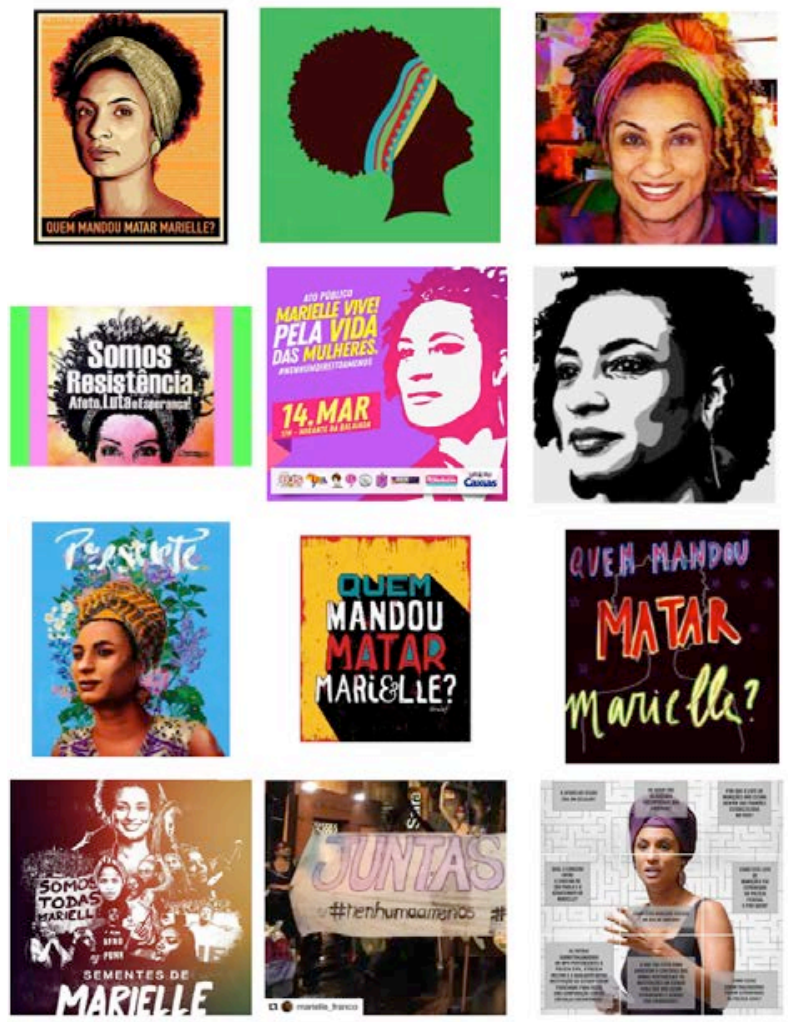

Figure 2: captured images from the \#mariellepresente feed on Instagram.

\section{DISOBEDIENT NARRATIVES: REMIX POETICS AND VISUAL GUERRILLA}

The imagery produced by autonomous collectives, non-partisan activist groups and above all ordinary citizens, mobilized and sensitized by the wave of political and social uprisings, represented a new aesthetic wave of post-internet visual narratives.

The activist inclination of these "cards" infected everyone with a desire for a political and social uprising aimed at breaking through boundaries, saying enough is enough, voicing what needs to be said.

The most striking political facts leading up to the presidential election constitute the framework for analyzing the aesthetics of activist visual narratives online and the relationship of images with the content conveyed. We archived the images posted under the same algorithm (hashtag): \#designativista, \#desenhosopelademocracia, \#coleraalegria, \#elenao, \#ursal, \#lulalivre, \#mariellepresente. These illustrated themes reflect a graphic and visual reaction to the government program of the then candidate Jair Bolsonaro. 
These message-images represent an excellent means of mass communication of the classes throughout history. I borrow the term "disobedience" from Frédéric Groac (2018) in order to name the dissenting, disobedient political narratives that refuse to obey an order they disagree with and that seek to resist, transgress and manifest themselves through nonconformity.

We are facing new discourses and experimentations with new languages. We are analizing Brazilian activist images but this is happening all over the world, such as "be water" demonstrations in Hong Kong, with anti-Trump demonstrations in the U.S., climate change, and feminist protests all over the globe, among others. Besides, there is a wide range of works and artists that we could use as visual reference to help us better understand the aesthetics of design and online activist communication.

Didi-Huberman's exhibition "Uprisings" (2018) is a curatorial reference for analyzing these images from a qualitative, formal and aesthetic point of view. In this work, the scholar and curator articulate literary, theatrical and visual arts references to compose the narratives of the exhibition. By displaying works with very heterogeneous languages, Didi-Huberman shows how activist imagery is inspired by and/or makes use of numerous languages. "They are 'desire-images', capable of serving as models for crossing borders", the author and curator states in the opening text of the catalog (Didi-Huberman, 2018, p.15). The concept of "desire-image" causes us to reflect on the reason why these images move us and make us wonder about the fragility of dissident battles and the power of art as an instrument and as a voice of new messages. The collective character and the aesthetic production of the ordinary citizen, the anonymous artist, is another feature of this very diverse imagery. In Rancière's view: " the distribution of the sensitive and the glorification of "any one".

Rancière states that it is precisely in the aesthetic field that the political discussion, the generalization of the spectacle and the multiplication of discourses are held today. We are constantly giving visibility to social, cultural and political relations, thus producing our discursive manifestation in the field of aesthetics. The author proposes a new aesthetic regime for the arts, in which "the aesthetic revolution is first and foremost the glory of anyone" (RANCIÈRE, 2005, p.48). This principle gives visibility to the anonymous subject, who is capable of producing art and also assigning beauty to other modes of representation, devoid of systems and visual arts' hierarchies of representation genres. In this new aesthetic regime, what is banal becomes beautiful as a trace of that which is true. The legitimacy of the narrative navigates through fiction, through the representation of what is beautiful, so that we are able to reflect upon history or the event. Thus, the arrangements between the signs of the real and of the images, the relationships between what one sees and what one says and between what one does and what one can do are discussed by way of language. (Prata, 2016).

\subsection{Remix Culture}

In the case of the narratives selected in this article, it appears that documentary and "real" images blend with fictional creations on the same theme. They are displayed side by side and are subordinate to the written code. Under the same \# preceded by the keyword. The \#s have a dual role: they serve as captions for application users to name their activist acts as well as metadata. The continuous reading of this sequence of fragmented and heterogeneous images engenders new interpretations and other meanings. These images belong to a new language operation, from the production process and the posting, the archiving on application repositories, to the way they are viewed on the application screen. These operations are mediated by algorithmic data and represent one of the forms of database visualization.

Adding images from various sources (of often unknown authorship) in a remix of appropriated images characterizes today's global culture. In the new forms of language production, issues such as fake images, fictional images, collaboration and collectivity are part of the creative process (Navas, 2016).

Navas analyzes how the regenerative remix acts as a bridge to the future of culture in which the ephemeral use of images, text, and sound digitally produced, reproduced, and efficiently archived on data can be used for various creative endeavors. This term relates to connectivity, the use of mobile devices, smartphone cameras and the constant flow of information exchanged on social networks and the web. In the author's view, social media could be considered a part of the regenerative remix in terms of discourse.

The new language manifestations of regenerative culture happen when an element is recycled in a way that it is recognizable in a new visual proposal. The recycling of such material available online is the main characteristic of regenerative culture.

Activist narratives constantly feed on the flow of images, texts and audios from social networks. In practice, they constitute a fragmented and continuous narrative, with daily uploads and thousands of posts a day. Regenerative practice is also evidenced in posts in which there is explicit visual appropriation. When one analyzes the interplay of the visual narrative compositions online, it is impossible not to relate the aesthetic influence of activist posters produced in other periods of history with the aesthetics of appropriation and remixing of the posts produced for the networks.

The manifestation through posts, or rather, the activist visual communication on the networks 
relates to the production of activist posters and other artistic works of the late 60 s and early 70 s in Brazil and around the world. The formal aspects of posters - colors, composition, typography, and serialized, copied, imitated, appropriated repetition are also relevant for examining the online visual culture as a regenerative art.

It is possible to draw a parallel between the 2018 posts and the manifestations of the late 60 s and early 70s. These were strongly linked to the dictatorship (in Brazil and later in other Latin American countries such as Argentina, Uruguay and Chile). Also, in other European countries and and in the the U.S., they were related to social, and political uprisings, as "May 68" demonstrations, the struggle for feminism, anti-racism, and so on.

Looking at the graphic design related to this production, we could say that the digital "cards" (posts) are analogous to printed or handmade posters. However digital "cards" do not circulate in the streets but in the flow of networks and can be reposted and conveyed infinitely.

Another interesting comparison (not covered in this article) would be to analyze the current activist posts related to the worldwide manifestations concerning racism, feminism, fascism (\# metoo, \# ihatetrump, \#ImpeachTrump, \#womensmarch, \#nobrexit, \#giletjaune). These are questions that address the importance of graphic production archiving for Instagram, so as to discuss the global and local languages, homogeneity and the remixed graphic language of networks. They are images made from a specific visual reference, as can be seen below.
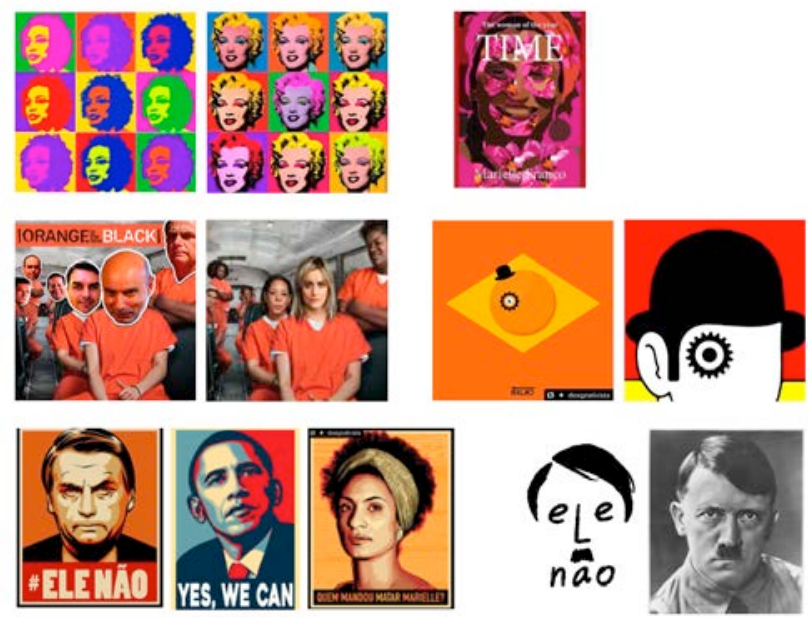

Figure 3.Instagram's images and heir correspondent apropriation/reference: Andy Warhol's screenprint from 1967, with the s ilhouette of $M$ arilyn Monroe in high contrast and the arrays of $c$ olored $s$ quares, $i$ s us ed in the $c$ omposition with Marielle's image; Cover page of Times Magazine "Woman of the Year" is used as a framework for Marielle's picture, leaving one to wonder if the subject, murdered in March 2018, was in fact selected by the publ ication; "Orange Is the Ne w B lack", the
Netflix s eries, i s us ed for the "orange $c$ ase" $i$ nvolving ghos $t$ Congress candidates from Bolsonaro's party; The iconic poster of Stanley Kubrick's 1971 fi Im "A Clockwork Orange" is used to illustrate the "orange case"; The poster that marked Barack Obama's 2008 US election campaign, designed by illustrator and ac tivist Shepard Fairey, is us ed as a r eference for vector illustration I anguage and al so for the $c$ omposition of pos ts of political figures Bolsonaro and Marielle; Hitler is revisited as Bolsonaro in the brush strokes of designer Eduardo Foresti.

There is an anthropophagic aspect to these message-images. The game of addition, multiplication and subtraction of the visual elements of the posts promote formal associations and constitute a unique aesthetics of online graphic memory. In the light of activist design and media art, these images constitute a rich visual archeology.

\section{OVERPRODUCTION OF IMAGES, ARCHIVISM AND GRAPHIC MEMORY}

The ephemerality of the online production of cards, based on daily events and statements made in the media (Twitter, TV, printed-press, internet, blogs, Facebook, Instagram) is characterized mostly by its volatility. Such production is already born adrift, and loses its tracks and roots to compose the media stream of news feeds. Paradoxically, the sequence of posts viewed in the app's feed constitutes a great polyphonic and unisonous message on the same theme.

Removing these thematic narratives from the media stream and curating these images through the database visualization methodology means organizing our current memory, which is already born with amnesia, as there is no guarantee that a certain image/card /post will be viewed or shared.

The authorship of posted images often goes unnoticed or is "forgotten" as it shifts to other contexts, or is appropriated in the assembly and editing of other cards/posts. However, the greater the engagement of ordinary citizens in the production of these images, the more enriching the remixed vocabulary of this aesthetic production in terms of a qualitative sample. And perhaps more standardized in terms of aesthetic standardization. This is one of the points observed:

(i) The number of images posted under the same \# can be huge. Capturing the \#elenão images posted specifically on the day of the demonstrations (September 29) would require days of image downloading and a gigantic storage capacity $(700,344$ posts by 5/20/2019).

(ii) These metamorphic narratives are not archived by the applications or by their authors. 
(iii) The post made in the heat of events gets lost in the media stream and the archive gets lost over time.

(iv) Instagram and Facebook apps do not allow search by date or theme. The act of tagging the images remains even after the election.

By viewing, for example, the \#elenao ("not him") and \#desenhospelademocracia ("drawings for democracy"), we find that these narratives are continuous, tending to infinity. Besides, new visual components are being added to suit the dissident context of the moment when the cries of "ele não/not him" or "drawings for democracy" still resonate. These are emblematic themes are still on the agenda in this first year of government.

\section{NEW PARAMETERS FOR ACTIVIST IMAGE CLASSIFICATION}

A curatorship of images from networks that represents the Brazilian graphic memory is a subjective selection - it depends on the curatorial gaze and is based on historical and cultural evidences, mainly those of visual language relevance. This process feeds on qualitative and quantitative analyses. Working with a small sample of images selected only by \#s revealed some aesthetic patterns and illustrated certain trends.

In the cognitive analysis of this large set of images, we observed some recurring aesthetic patterns and the need to classify them in light of other formal parameters.

The author has established seven aesthetic categories:

(i) Factual: appropriated documentary photographs related to the fact or character. There could be text interventions. Works characterized by unpolished composition and collage due to the hastiness in which the material is produced to be posted. What matters is active participation on the network in near real-time.

(ii) Memes: (subcategory of "factual"): memes are a subcategory of factual posts. However, there is some elaboration in the message, usually in a more satirical/humorous tone. These posts are characterized by images appropriated from media (TV stations or online newspapers) and consist of a black upper and/or lower banner on which text is applied. They go viral more easily on the network. (iii) Digital illustration: figurative or abstract vector illustrations made from a specific theme. They represent visual syntaxes. Digital collages with use of photographs also fall into this category.

(iv) Digital typography: typographic posts. Digital compositions, made on the application.

(v) Free-hand illustration: cartoons, free-hand drawings, comics, signed or unsigned works.

(vi) Vernacular typography: handmade posters, handwritten posts, regionally inspired illustrations, references to Russian avantgarde visual language.

(vii) Appropriation: posts in which there is an appropriation of the image from a movie poster, a Netflix series, a comic strip, a newspaper page, an artwork or a wellknown photograph.

These categories were first applied to the cognitive classification of 6,000 images. However, this sample may conceal a specific trend, it may not not highligh other aesthetic patterns of the vast production circulating on Instagram. Archiving a larger number of images means broadening the understanding of this new visual vocabulary. Also, the use of artificial intelligence proved fundamental to this endeavor.

\section{MACHINE LEARNING AND ARTIFICIAL INTELLIGENCE}

The idea of proposing our own classifiers for analyzing images comes from the need to qualitatively measure the aesthetic diversity produced and shared on Instagram.

Does this diversity culturally represent the local graphic production? Which influences are local, which are global?

The initial sample classification of 1,000 images of each category was used for supervised machine training and learning in the creation of seven image classifiers (labelers): Factual; Digital illustration; Digital typography; Free-hand illustration; Vernacular typography; and Appropriation.

We built the data library by including these targets (images with features to train the machine in each category). The labelers are still being tested. However, even without the conclusion of the reading of all the narratives by the classifiers, the discussion around the use of $\mathrm{Al}$ as a part of the archiving selection process points in some interesting directions. 
In view of digital culture and artificial intelligence aesthetics, we can problematize data visualization, group engagement and the use of bots and algorithms to verify the standardization (or proliferation) of network image language (Manovich, 2018).

For the author, "The scale of digital culture demands intelligence that is qualitatively similar to a human, but operates on a quantitatively different scale... How best to match Al with human skills?" (Manovich, 2018).

Regarding the standardization of the global aesthetics of images circulating in digital media, Manovich comments on how Al is used by various photography applications available for download by any user. These apps provide tags and parameters related to types of focus, color filters, composition and taggings such as "portrait", "food", "landscape" etc. These models, previously available to plugand-play users, end up automating and suggesting pre-established aesthetic patterns - the standardization of photo imagination. (Grigonis, 2016; apud Manovich, 2018). On the other hand, there are more and more applications and websites for different media that allow the customization of services. Al has also increased the diversity of these functions, and these algorithm changes, increasingly present on networks and other media, allow for a wide range of infinite combinations.

Instagram itself uses datasets that determine how images are viewed: posts are programmed to be viewed first within your immediate circle of followers, that is, within your "bubble" of friends or acquaintances who think like you, interact with the same kind of news etc. The experience of the user, their shares, likes, and repost engagements are shaped by the visual experience constrained by the application's algorithmic filters. Searching, for example, for \#designativista ("activist design") on Instagram, what I see on my feed as "top posts" is different from what someone who does not belong to the same group of followers sees.

In other words, Instagram's institutional visualization is set for you to see first the images of friends and friends of friends with whom, in a way, you have more aesthetic affinity. This enclosed and manipulated environment acts like a virus, a "contagion" of a visual language lexicon, encouraging the production of new cards that follow the same "collective" aesthetic - one that has already been created by someone and appropriated and remixed. Therefore, an identificational visual pattern is created, in which your peers, followers, friends and family feel represented. There is some aesthetic comfort, something "strangely familiar" - to quote Freud -, as the visual elements, the colors, the typography refer to something revisited, something already known. Something viewed and reviewed. In order to extend the qualitative sample of the cultural production, thus showing the diversity of the national production, we need to look for differences, for what is ahead of the curve and new in an abundant sampling. Therefore, redundancy and quantity are welcome in this research.

\section{CONCLUSION}

The visuality of the narratives read by the labelers developed for the project may present unusual and unprecedented aesthetic patterns. After all, what do machines read as "digital illustration", what is the pattern for recognizing factual images? We still do not have the answer to how machines process and read activist narratives in these 7 thematic axes. However, the results obtained so far have been positive and relevant to contribute to our discussion of which strategies should be used in archiving social media art production. Besides, it raises questions that are still open: Who decides what to archive as Brazilian graphic memory posted on networks? How to archive them and how to make them accessible to a larger public?

The political and sociocultural context promotes language production. If this production is recognized as counterculture, activist, dissident by institutions and the current political regime, who ensures that this graphic memory will be archived as part of our history?

We live in a moment where the politics of forgetting reigns absolute and activist narratives need to be archived so that we remember not to forget our recent past (Beiguelman, 2019).

The present work understands the production of images for networks as a graphic piece to be categorized in terms of graphic design as a material object that is representative of the culture and the national sociopolitical context.

Such pieces represent the "graphic memory" (BRAGA, FARIAS, 2018) of graphic design in the age of networks. 

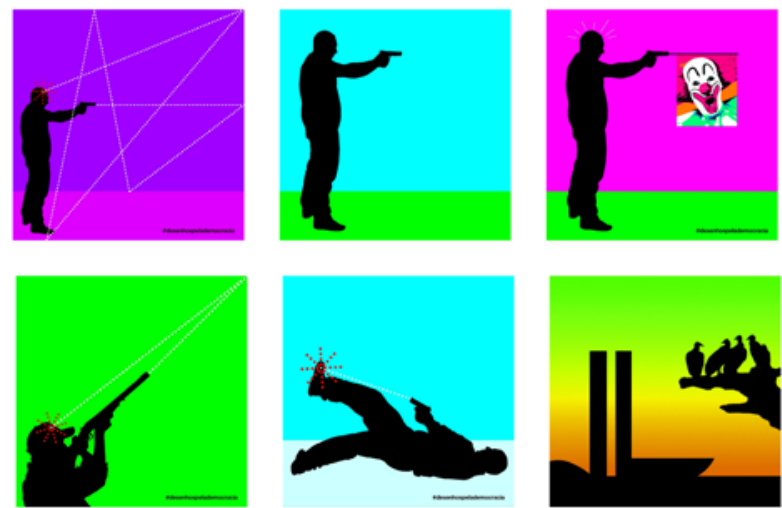

Figure 4: Narrative about the use of fire weapons, by @Daniel Trench, edited by \#desenhospelademocracia
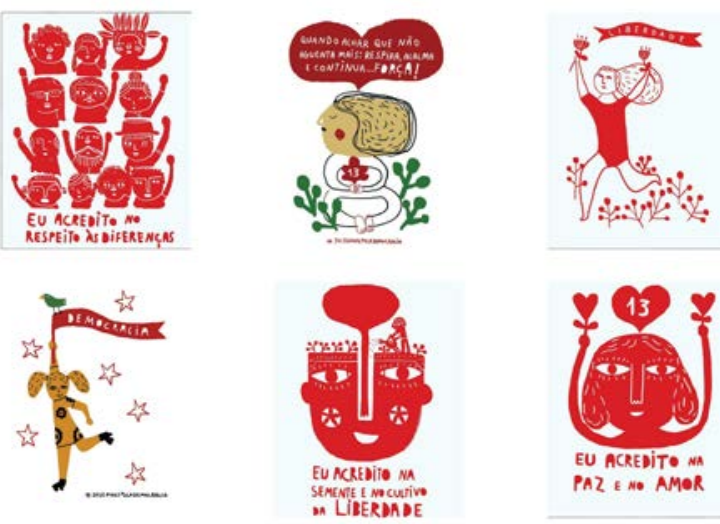

Figure 5: Narrative about democracy illustrated by @lucisacolera, edited on \#desenhospelademocracia

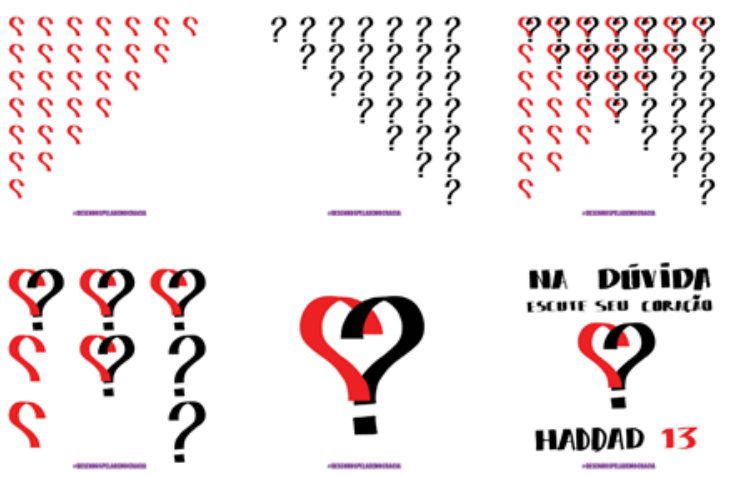

Figure 6: Narrative about "vira voto" ("change votes"), by unknown author, edited on \#desenhospelademocracia

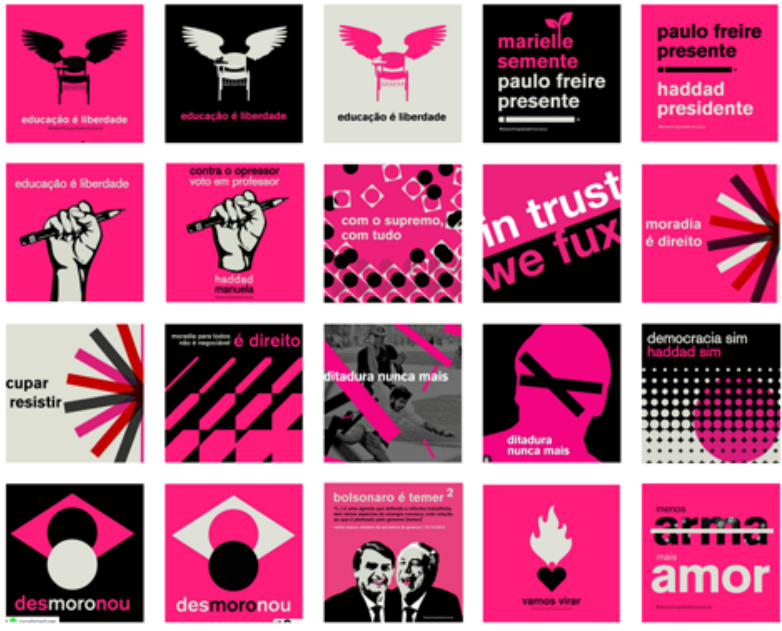

Figure 7: Posts created by the collective Bijari, edited on \#designativista, \#desenhospelademocracia

The use of machine learning and Al for curatorial research and artistic creation is an interesting artistic and classificatory strategy that requires the co-participation, in all stages of the process, of human decision. One of the potentialities related to archiving these images using $\mathrm{Al}$ is that it may be used to create new design pieces, applications or websites that can give visibility to dissident narratives.

The use of image classifiers has also been applied in the creation of new visual narratives projects, in order to archive the Brazilian political graphic memory as a potential dissident graphic design vocabulary. As the website "Dissident Calendar" (http://calendariodissidente.fau.usp.br/), created by the author.

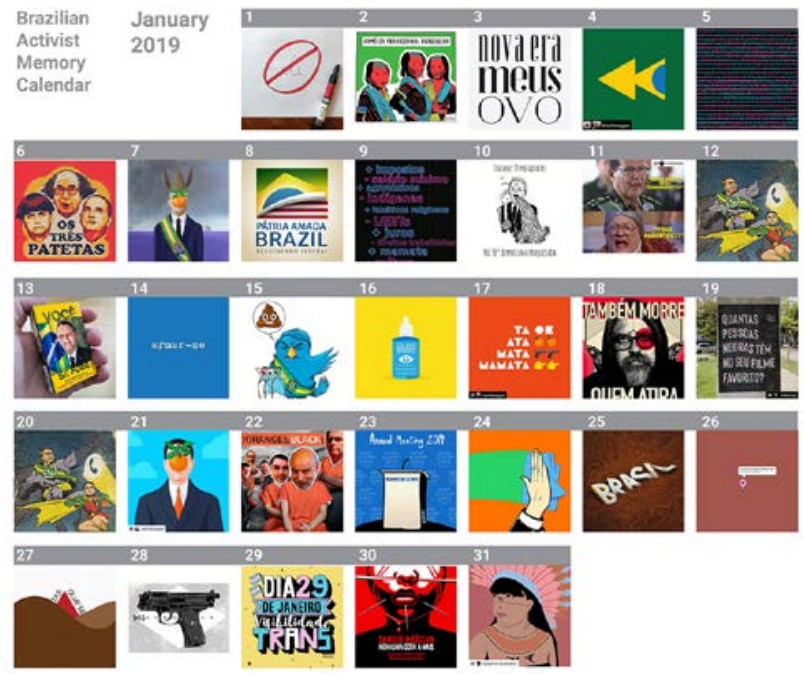

Figure 8: Page layout of the website "Dissident Calendar" (http://calendariodissidente.fau.usp.br/). 
Historical references are still fundamental in the analysis of activist production today. Cataloging activist production through the lens of design means giving up the linearity of temporal references and shifting to any period, in layers, like a rhizome.

As we broaden the analysis of visual examples with the use of $\mathrm{Al}$, we come into contact with other features of these graphic pieces or material objects (artifacts). They are not stationary objects; they are in constant displacement and interaction. Al's aesthetic field is still at an early stage and it is likely to grow in the coming years. It is up to us researchers, designers and artists to decide how to use it to our advantage, exploring its potential for creative and archivistic use, among other purposes.

The essence of digital activist narratives is not institutional. They are disobedient, insistent, fastmoving. These are poor images made for traveling in low resolution (Steyerl, 2009). Or rather, they are rich images, rich in being free and detached from any pre-established aesthetic rigidity. Moreover, they do not belong to conventional institutional representations, in the governmental (of surveillance and control) or corporate (commercial) sense, and are on the fringes of the rules of mainstream cultural production (image and authorship copyrights). They cannot depend on application viewing restrictions to be archived or accessed. They represent, in essence, Rancière's distribution of the sensitive.

\section{REFERENCES}

\section{Book:}

Beiguelman, Giselle. (2019) Memória Da Amnésia: Políticas $D$ o Esquecimento. São Paulo. Edições SESC.

Bratton, Benjamim. (2015) The Stack: On Software and Sovereigntly, MIT Press, 2015.

Costa, Marcos; Farias, Priscila. (2018) dez ensaios sobre memória gráfica. São paulo. Blucher.

Didi-Huberman, Georges.( 2017) O que vemos, o que nos olha. São Paulo: Editora 34, 1998.

Paulo.

(Org.). Levantes. Edições Sesc São

Flanagan, Mary. (2007) Play, Participation and Art: Blurring the Edges. In: LOVEJOY, M. et al. (org). Context Providers: Conditions of Meaning in Media Arts. Bristol, UK/Chicago, EUA: Intellect.

Flusser, Vilém. (2007) O m undo c odificado. São Paulo: Cosac Naify.

Glaser, Milton; ilic, Mirko; heller, steven. (2017) The Design of Dissent, Gothan books, New York.
GROS, Frèdèric.(2018) Desobedecer. São Paulo. Ubu Editora.

Manovich, Lev. (2001) The Language of New Media.Massachusetts: MIT Press.

. Al Aesthetics. (2018). E-book Kindle.

Prata, Didiana. (2016) Imageria e poét icas de representação da paisagem urbana nas redes. 2016. 220 p. Dissertação - Faculdade de Arquitetura e Urbanismo da Universidade de São Paulo, São Paulo.

Rancière, Jacques. (2005) A partilha do sensível: estética e política. São Paulo: Editora 34. . O destino das imagens.(2013) Rio de Janeiro: Contraponto.

\section{Book Chapter:}

Paul, Christiane. Contextual Networks: Data Identity and Collective Production. In: LOVEJOY, M. et al. (org). Context Providers: Conditions of Meaning in Media Arts. Bristol,UK/Chicago, EUA: Intellect, 2011.

\section{Journal article:}

Steyerl, Hito. In defense of the poor image, eflux Journal, n. 10, nov. 2009.

\section{Catalogue:}

Technopolitics. (2018) Tracing Information Society.

\section{Internet source:}

Navas, eduardo. (2017) Regenerative Culture. In: Norient Academic Online Journal. Disponível em: $<$ https://norient.com/tag/regenerative-culture> in june 2017. 